\section{BASES EPISTEMOLÓGICAS DEL DEBATE SOBRE EL SEXISMO LINGÜÍSTICO}

\author{
María Márquez Guerrero \\ Universidad de Sevilla \\ mmarquez@us.es
}

\section{EPISTEMOLOGICAL BASES OF THE DEBATE ON LINGUISTIC SEXISM}

Cómo citar este artículo/Citation: Márquez Guerrero, M. (2016). "Bases epistemológicas del debate sobre el sexismo lingüístico". Arbor, 192 (778): a307. doi: http://dx.doi. org/10.3989/arbor.2016.778n2010

Recibido: 08 septiembre 2015. Aceptado: 14 septiembre 2015.
Copyright: (C) 2016 CSIC. Este es un artículo de acceso abierto distribuido bajo los términos de la licencia Creative Commons Attribution (CC BY) España 3.0.
RESUMEN: En este trabajo analizamos los supuestos epistemológicos que subyacen a las diferentes posturas en torno del tema del sexismo lingüístico: la dicotomía lengua / habla; la independencia vs. condicionamiento de la lengua con respecto a la realidad; el principio de arbitrariedad, la confusión entre referencia y referente, etc. Defendemos la natural motivación del género en los sustantivos animados con referencia personal, y tratamos de mostrar que la vinculación entre género y "sexo" no implica la confusión de los planos de la lengua y la realidad, pues el "sexo", que actúa como motivador, lo hace como taxema de la experiencia, sustancia semántica conformada lingüísticamente. Dada la afirmación de este vínculo, se comprende la espontánea creación de femeninos específicos, que es una tendencia estructural de nuestra lengua desde sus orígenes. Por otra parte, el uso abusivo del masculino "genérico", utilizado en contextos específicos, de pertinencia, donde no es posible la neutralización, explica un uso sexista que oculta a la mujer naturalizando su ausencia.

PALABRAS CLAVE: Discurso sexista; género y "sexo"; invisibilización de la mujer.
ABSTRACT: This paper analyses the epistemological assumptions of the different approaches to the subject of linguistic sexism: the dichotomy language / speech; independence vs. conditioning of language by reality; the principle of arbitrariness; the confusion between reference and referent, etc. We defend the natural motivation of gender in animated nouns with personal reference, trying to show that the relationship between gender and "sex" does not imply confusion of the planes of language and reality, for "sex", which acts as a motivator, does it as a taxeme of experience, semantic substance conformed linguistically. Taking into account this link, we understand the spontaneous creation of specific feminines, which is a structural trend of our language from its origins. On the other hand, abuse of the "generic" masculine, used in specific contexts -contexts of relevance, where neutralization is not possible- explains the concealment of women, and a naturalization of their absence.

KEYWORDS: Sexist discourse; gender and "sex"; invisibilization of women. 


\section{INTRODUCCIÓN: UNA BREVE APROXIMACIÓN DIA- CRÓNICA}

E en esta carta escriuiemos fijo et non escreuimos fija; et por ende escribimos que si don Alvaro no touier fijo, et fija ouiere de tal casmiento cummo desuso es dicho, que ella sea en esta carta en logar del fijo que de sus es dicho (Menéndez Pidal, Documentos lingüísticos de España, Toledo, 1239, no 279)

Comenzamos con este ejemplo, tomado de un texto del siglo XIII, que nos muestra el uso del masculino en un plano inespecífico sin el valor genérico que hoy resulta tan "incuestionable". La necesaria aclaración "si non touier fijo, et fija ouiere... que ella sea en esta carta en logar del fijo que de sus es dicho" muestra que el masculino singular no incluía la referencia femenina a pesar de encontrarse en un enunciado inespecífico. La histórica vinculación del morfema de género con el contenido lingüístico de "sexo" justifica la necesidad de precisión. Hoy día utilizaríamos la expresión "descendencia" o "descendiente(s)" para evitar el equívoco en la identificación referencial, fenómeno que, como vemos, no es invención de la crítica feminista al lenguaje sexista, ni tampoco una estrategia "políticamente correcta", sino sencillamente el resultado de la ambigüedad provocada por el doble valor del masculino. La perspectiva diacrónica nos muestra como algo natural la adopción de medidas para facilitar la asignación referencial de manera clara y precisa en el caso de los sustantivos con referencia personal. Así, los desdobles y otros recursos inclusivos de la referencia a la mujer tampoco son extraños en los textos medievales:

Mio Çid Ruy Díaz por Burgos entrava, / En su conpaña sessaenta pendones. / Exiénlo ver mugieres e varones, / Burgeses e burgesas por las finiestras son, / Plorando de los oios, tanto avién el dolor (Poema de Mio Çid, 1, 3, vv 15-20).

En el latín no había morfema específico de género. Había femeninos en -US (como PINUS) y masculinos en -A (como POETA). Al desaparecer el sistema de casos, se descubrió en el género un medio adecuado para expresar las relaciones sintácticas a través de la concordancia. Las vocales desinenciales $-a,-o$ se llenaron de contenido de género, asociándose la -o con el masculino y la - a con el femenino, porque la mayor parte de los sustantivos de la segunda declinación, mayoritariamente masculinos, tenían como vocal temática la -0 ; y la mayor parte de los sustantivos de la primera declinación, con vocal temática $-a$, eran femeninos. Una vez que se le reasigna a ese segmento fónico un contenido genérico, lo que ocurre en la historia de nuestro idio- ma es que se reajusta la terminación para adecuarse al género o al revés. Como señala Zenenko (1983), en la evolución del latín a las lenguas romances se acentuó la dependencia del género respecto de la estructura fonológica del vocablo. Junto a la motivación fonológica, se halla también la motivación etimológica: los cultismos griegos en -a (drama, clima, planeta, tema) se han ido fijando en español como masculinos, a pesar de su terminación, por estar fuertemente motivados etimológicamente. En la evolución al romance castellano también desapareció el neutro, pues aunque pueda haber palabras o expresiones con un contenido "inespecificado", no hay morfo en español que exprese el contenido neutro del género.

Una vez que las terminaciones $-a$ / -o se han cargado de contenido genérico (metalingüístico siempre: 'femenino' / 'masculino'; y, en algunos casos, también lingüístico: '+'hembra' / -'hembra') será un hecho muy frecuente la creación de femeninos específicos desde los orígenes del idioma: por ejemplo, los agentivos en -or, como trabajador, no tenían forma femenina en los primeros tiempos del castellano, como tampoco los gentilicios en -és; hasta el siglo XVI encontramos en los manuscritos expresiones como "mulher portugués" (Zenenko, 1983); es el mismo caso de las múltiples creaciones analógicas que comienzan como variantes de uso y hoy son voces admitidas por la Real Academia Española (RAE), como médica, arquitecta, presidenta, modisto, etc. La misma motivación se observa en la ocurrencia de "monstruos sintácticos" (Reyes, 1998, p. 21) como la médico, tan contrarios al sistema y sin embargo tan generales en el uso. A lo largo de los siglos, los hablantes -que vinculan espontáneamente el género gramatical con la idea de "sexo" en el caso de los sustantivos con referencia animada, sobre todo [+humana]- crean formas como señora, infanta, parturienta, etc. No parece científico afirmar que los hablantes caen en "el error de confundir género y sexo", o que son víctimas de alguna ideología feminista radical cuando a lo largo de los siglos han ido creando todas estas formas, muestras de una tendencia espontánea y estructural de nuestra lengua.

\section{LOS ESTUDIOS SOBRE EL SEXISMO LINGÜÍSTICO y SUS FUNDAMENTOS EPISTEMOLÓGICOS}

En los estudios sobre sexismo lingüístico pueden distinguirse dos posturas teóricas enfrentadas (Pérez García, 2007):

a) Aquellos que defienden la independencia de la lengua con respecto a la realidad. Apoyándose en el carácter arbitrario del género, 
estos autores afirman que el sistema de la lengua no es sexista, aunque sí pueda serlo su uso, de ahí que no consideren necesario crear femeninos específicos ni modificar en nada los usos lingüísticos.

b) Quienes parten de la interrelación entre lengua, pensamiento y realidad afirman que la lengua, en general, y la categoría del género, en particular, reflejan la organización social patriarcal dominante en las sociedades actuales. Por esto, defienden la intervención activa en la lengua, herramienta que puede utilizarse para la transformación social.

Ya a primera vista, se advierte que en el tema están implicadas cuestiones teóricas y metodológicas fundamentales para la lingüística, tales como la relación entre lengua - pensamiento - realidad, o la dicotomía lengua / habla.

\section{1. ¿Es sexista la lengua o lo es el uso que hacen los hablantes de ella?}

Es clásica la pregunta sobre si es sexista la lengua o si, en cambio, lo es solamente el uso que los hablantes hacen de ella. Así, por ejemplo, García Meseguer, a quien debemos una sistematización y clasificación de los fenómenos sexistas del español, en un primer momento (1977) defendió la existencia de "sexismo lingüístico" distinguiéndolo del "sexismo ideológico" para no confundir el plano social, de la realidad, y el plano lingüístico. En publicaciones posteriores (1997), sin embargo, modificó su posición primera sosteniendo que no había tal sexismo en el sistema de la lengua, sino exclusivamente en el uso que de ella hacen los hablantes; a este respecto acuñó las expresiones de "sexismo del oyente" y "sexismo del hablante". De esta forma transfería el fenómeno desde el sistema de la lengua a la mente de los hablantes/oyentes. Mucho se ha discutido desde entonces sobre la existencia o no de rasgos y recursos sexistas, unas teorías a favor y otras en contra, pero todas compartiendo la distinción básica de sexismo en el sistema / sexismo en el uso. Sin embargo, si entendemos la clásica división entre lengua / habla como una clasificación epistemológica que supone la consideración de dos puntos de vista posibles a la hora de acercarse al hecho real único que es la lengua, deja de tener sentido tal pregunta. La dicotomía pertenece al plano de la investigación y no al de la realidad; así la concibió el propio Saussure, como muestra Benveniste, que reproduce las palabras del maestro:
Por lo demás hay cosas, objetos dados, que somos libres de considerar luego desde distintos puntos de vista. Hay aquí ante todo puntos de vista, justos o falsos, pero solo puntos de vista, con ayuda de los cuales son creadas secundariamente las cosas. [...] En lingüística negamos en principio que haya objetos dados, que haya cosas que continúen existiendo cuando se pase de un orden de ideas a otro, y que uno pueda por consiguiente considerar 'cosas' en varios órdenes, como si fueran dadas por sí mismas (Saussure, 1945/1981, pp. 57-58)

Deslindados bien los ámbitos de la investigación y la realidad, si aceptamos que la dicotomía de lengua y habla no es una oposición material, sino metodológica, "sería, pues, abusivo plantear preguntas materialmente disyuntivas, como, por ejemplo, si un fenómeno debe ser clasificado como hecho de lengua o como hecho de habla" (Heger, 1974, p. 139). No tendrán, pues, ningún fundamento todas aquellas observaciones referidas a ciertas características propias del "uso", que estarían, sin embargo, ausentes de sus respectivas lenguas.

\subsection{La lengua, el pensamiento y la realidad}

Otra cuestión epistemológica que subyace al planteamiento del tema del sexismo lingüístico es la relación de independencia vs. condicionamiento entre lengua y realidad. Quienes defienden que las lenguas no son sexistas parten de la afirmación de la independencia entre ambas basándose en el principio de arbitrariedad, uno de los pilares sobre los que se asienta nuestra tradición lingüística. Así, sostienen que toda la investigación sobre el sexismo lingüístico adolece de una confusión elemental entre el género -plano gramatical- y el sexo, perteneciente a la realidad. Es cierto que la dependencia tradicional de la Gramática respecto de la Lógica llevó a los gramáticos a basar las distinciones lingüísticas en delimitaciones extralingüísticas; el género, por ejemplo, se definía como "el accidente gramatical que sirve para indicar el sexo de las personas y de los animales y el que se atribuye a las cosas" (Gramática Académica de 1920, ap. 10). Se trataba de un trasvase de las categorías lógicas a la Gramática: las palabras se consideraban como símbolo de los conceptos, del mismo modo que éstos lo eran de los objetos. Hoy nadie acepta que la realidad esté perfectamente organizada y delimitada en categorías previamente existentes, cuyo reflejo conceptual tendría una traducción directa en las palabras (Martinet, 1978, pp. 17-19). El rechazo de esta dependencia llevó al extremo de negar cualquier conexión de la len- 
gua con la realidad so pretexto de no confundir ambos dominios. En el aspecto concreto que nos ocupa, la necesidad de alejarse de una definición nocional del género condujo a su consideración desde un punto de vista puramente formal, rechazando cualquier contenido lingüístico a él vinculado. Sin embargo, manifestarse en contra de la identificación de género gramatical y género natural, por ejemplo, no implica rechazar que, en ciertos casos, el género remite a un ámbito de referencia designativa correspondiente a una parcela de la experiencia, a saber, el "sexo".

El rechazo del "sexo" como motivador del género en español tiene en su base la confusión entre significación y designación entre referencia y referente; entre la sustancia de contenido conformada lingüísticamente, el concepto "sexo" y la realidad biológica correspondiente. La lengua no es una representación fiel o reflejo de la realidad, pero sí refiere la realidad, puesto que el lenguaje es significado, aprehensión del ser de las cosas, captación de la realidad. Con mucha frecuencia, se confunden la noción de referencia y de referente hasta el punto de tenerlos por sinónimos. La referencia se define en relación con la unidad léxica, y no tiene que ver necesariamente con una situación de enunciación concreta. Así, por ejemplo, la referencia genérica no alude a un segmento de realidad efectiva, sino a la categoría con la que está relacionado. Es la asociación de un signo con un contenido que se halla fuera de la lengua como sustancia semántica, es decir, con una conceptualización de cierta parcela de la realidad. En adelante, cuando hablemos del contenido de "sexo" no nos referiremos al sexo biológico, accidente del mundo real, sino al "sexo semántico" (Roca, 2005) como sustancia de contenido conformada lingüísticamente, taxema de la experiencia (Arias Barredo, 1995, p. 30, n. 38).

El estudio del género gramatical se presenta como algo muy complejo, dada la heterogeneidad de su manifestación formal (morfológica, sintáctica, ¿léxica?) y la "desconcertante diversidad semántica" (Morera, 2011) que muestra, esto es, la variedad de sustancias sobre las que informa ("sexo", "tamaño", etc.). De ahí que muchos autores hayan rechazado el estudio de su componente semántico ateniéndose exclusivamente a su dimensión formal de concordancia, postura que no resuelve el problema del valor interno del género, sino que simplemente lo evita fijando la atención en uno de sus aspectos secundarios, el aspecto distribucional o formal (Morera, 2011, p. 24). Aunque nadie discute que la concordancia "constituye la piedra angular del género en cualquier lengua" (Roca, 2005, p. 25), no parece conveniente eludir el estudio de su significado, pues una definición puramente formal del género no puede explicar, por ejemplo, la motivación que se observa en fenómenos como la abundante creación de femeninos específicos desde los orígenes del idioma. Con esa misma falta de discriminación entre referencia y referente, ciertos lingüistas hablan del "error" en el que caen los hablantes al "confundir de forma incorrecta lengua con realidad", género gramatical con sexo (J. A. Martínez, 2008; Roca, 2005 y 2006; Morera, 2011, o los 500 lingüistas que firmaron el manifiesto de apoyo a D. Ignacio Bosque en 2012, entre otros), "error" en el que también habrían caído muchos de nuestros doctos varones estudiosos de la gramática -desde los clásicos hasta la propia RAE- que admitieron la existencia de un vínculo entre el género gramatical y el "sexo" en cierto tipo de sustantivos.

Hay, pues, una resistencia evidente a admitir la función semántica del género; aunque se afirma que se trata de evitar la definición de elementos y categorías lingüísticas desde una perspectiva sustancial, creemos que, al menos en parte, se debe a que cuestiona los propios fundamentos epistemológicos de la lingüística estructuralista y generativista (ambas comparten la perspectiva inmanente en sus presupuestos teóricos): la idea de la lengua como "sistema" explicable en sí y por sí misma, y, por tanto, la absoluta independencia de la lengua con respecto a la realidad.

\subsection{El principio de arbitrariedad y la posibilidad de una motivación histórica}

Los que afirman que no existe ningún tipo de vinculación entre género y "sexo" se basan en una interpretación peculiar del principio de arbitrariedad del signo. Para empezar, es falsa la opinión de que fue Saussure el primero que formuló la teoría de la arbitrariedad. El concepto remonta a Aristóteles, que afirmó que el lenguaje no significa por naturaleza, sino "en cuanto establecido (o instituido)", planteamiento que no hacía referencia a la relación entre el sonido y el objeto designado, puesto que para él "Ios sonidos de la lengua no son signos para objetos, sino para contenidos "del alma" (Vilarnovo Caamaño, 1993, p. 30). Lo que realmente quería indicar es el carácter libre del lenguaje, el no estar determinado por la naturaleza de las cosas: los signos funcionan como tradicionalmente establecidos y, precisamente por ello, como históricamente motivados. Este sentido no fue captado con exactitud por los estudiosos posteriores, que formularon el problema desde una perspectiva genética y no funcional. Se centró la discusión en el problema on- 
tológico de la relación entre los nombres y la realidad extralingüística, y se interpretó el sintagma "según establecido (instituido)" como "resultado de un pacto o un acuerdo social", presuponiendo una voluntariedad en la fundación del signo.

El planteamiento de Saussure supone una vuelta a la interpretación aristotélica de "históricamente determinado": "con relación a la idea que representa, aparece el significante como elegido libremente" (1945/1981, p. 135), es decir, no hay ninguna razón natural que obligue a la elección de ese significante. Pero considerado socialmente, ese significante viene impuesto: "A la masa social no se le consulta, ni el significante elegido por la lengua podría tampoco ser reemplazado por otro" (1945/1981, p. 135). El propio concepto de arbitrariedad presupone el cambio: "Ya hemos visto cómo el carácter arbitrario del signo nos obligaba a admitir la posibilidad teórica del cambio" (1945/1981, p. 137); lo que ocurre es que ese cambio no podrá ser nunca individual ni tampoco fruto de la voluntad consciente y racional de la comunidad hablante. Ni el individuo, ni la comunidad a través de decretos o de lecciones magistrales podrán cambiar la lengua: solo la colectividad puede establecer valores cuya única razón de ser está en el uso y en el "consenso" generales. Por eso, Saussure afirmaba que el signo era a la vez mutable e inmutable, porque siendo arbitrario no puede ser puesto en tela de juicio en nombre de una norma razonable, pero precisamente por ser arbitrario, siempre es susceptible de alterarse:

Una lengua es radicalmente impotente para defenderse contra los factores que mueven, instante tras instante, la relación entre significado y significante. Es una de las consecuencias de la arbitrariedad del signo (1945/1981, p. 112).

Así pues, no hay ninguna contradicción entre la teoría de la arbitrariedad y el cambio lingüístico motivado histórica, cultural y socialmente. La misma evolución de las lenguas lo confirma. Cambia la realidad, se reorganiza conceptualmente la experiencia humana y se crean nuevas palabras y expresiones para designarla.

\section{EL INEVITABLE ENFOQUE DISCURSIVO DEL SEXIS- MO LINGÜÍSTICO}

La cuestión sobre si es o no sexista nuestra lengua no puede analizarse desde una perspectiva puramente inmanente. El tema que nos ocupa desborda el campo tradicional de la Gramática -si entendemos por tal el estudio de la lengua desde una perspectiva inmanente-, para situarse en el ámbito de la Pragmática Lin- güística; esto quiere decir que no consideramos posible su estudio sin integrar la referencia y el contexto en el que la lengua se actualiza. Aunque definiéramos el género de una manera puramente formal, no podríamos eludir jamás la referencia, pues la misma concordancia presupone la anáfora, que es, en sí misma, una operación referencial (Arias Barredo, 1995).

Partimos de la consideración del género como una categoría gramatical aunque su expresión no sea morfológica ( $n i \tilde{n}-o$ / niñ-a), y aunque no implique siempre una referencia a la realidad extralingüística. Si no reducimos la noción de significante a la de cadena fónica y consideramos que puede incluir propiedades como la concordancia, el orden, la valencia combinatoria, etc. (Trujillo, 1976; Gutiérrez Ordóñez, 1981) y no reducimos la noción de significado al contenido lingüístico, sino que incluimos en ella también la forma de contenido gramatical o metalingüístico, llegaremos a la conclusión de que se trata de un signo (no una figura de contenido, J. A. Martínez, 1978; ni un simple morfema desinencial, Roca, 2005) que se manifiesta siempre sintácticamente, a través de la concordancia, $y$, a veces, también morfemáticamente. Por otro lado, el contenido inherente al género corresponde, en algunos casos, a un referente lingüístico (campo léxico 'sexo') asociado a otro metalingüístico (campo gramatical 'género'); y en otros, los más abundantes (según Echaide, 1969, un $84 \%$ del léxico) el contenido del género es solo de orden metalingüístico; pero en ambos casos hay una forma de contenido asociada al género, lo cual justifica su consideración como signo. Estamos, por tanto, ante una categoría gramatical de carácter formal, que se manifiesta a través de una forma de expresión discontinua y a menudo redundante (Arias Barredo, 1995). En todo caso, el género proyecta su campo de acción más allá del sustantivo y el sintagma que constituye; esto quiere decir que el ámbito en el que el género se despliega y es reconocible es en el discurso. Por tanto, no podemos efectuar nuestro análisis situados en el universo de los signos, pues esta perspectiva lleva a confundir la categoría del género con su expresión morfemática. Así, algunos autores, señalan, por ejemplo, que no es necesario crear femeninos específicos, como jueza, pues argumentan que juez es un sustantivo común, que no indica género -ni por supuesto sexo- y que por tanto puede utilizarse para ambos referentes. En primer lugar, la afirmación supone la confusión del género con su expresión morfológica (González Calvo, 1979). Si consideramos la cuestión desde una perspectiva discursiva y asumimos que el género se manifiesta formalmente a través de los determinantes y adyacentes que acom- 
pañan al sustantivo en el enunciado, tendremos que admitir que el sustantivo será necesariamente masculino o femenino; siempre habrá oposición de género, aunque la expresión de este sea sintáctica y no morfológica: la juez / el juez. El hecho de elegir la forma de expresión redundante (la jueza, en lugar de la juez, como ocurre en la niña, también redundante) tiene que ver con la tendencia registrada en nuestro idioma desde los orígenes de marcar al femenino con $-a$ (Badía Margarit, 1967: "es evidente la tendencia del español a marcar los femeninos con $-a$ ").

En nuestra opinión, dos prejuicios generales impiden una comprensión clara de la categoría del género:

a) la confusión del género con la expresión morfemática del género, por un lado (González Calvo, 1979).

b) Y, por otro, la confusión de la sustancia (material o conceptual: las cosas y las ideas) con la forma del contenido; particularmente, la confusión del "sexo", sustancia de contenido conformada lingüísticamente, con la realidad biológica del sexo.

\section{LA TAN DEBATIDA CUESTIÓN SOBRE EL VALOR GENÉ- RICO DEL MASCULINO}

Desde el punto de vista lingüístico, el asunto primordial que ocupa a los investigadores es el de poder explicar, en el caso del género masculino de los sustantivos con referencia [+animada] y especialmente [+humana], la coexistencia del contenido específico "Hembra" = "macho" y, al mismo tiempo, su capacidad de hacer una referencia global auténticamente abarcadora de los referentes de ambos sexos. En principio, es un problema de orden lógico: hacer teóricamente compatibles en una misma forma la diferencia específica y la mención genérica:

El concepto ['descendiente', 'de I grado'= hijo] incluye tanto a machos como a hembras. Lo que no resulta admisible para nadie es que 'macho' incluya a 'hembra' (Arias Barredo, 1995, p. 49).

Para resolver la aparente contradicción lógica, muchos investigadores han rechazado la adjudicación al morfema de género de ningún tipo de contenido lingüístico. Es el caso de Roca (2005), que critica la "absurda vinculación entre el género y el sexo" tan general en nuestra tradición gramatical, y considera $-O /-a$ como morfemas desinenciales con un papel puramente clasificador. O también el de J. A. Martínez (1978), que señala que los contenidos lingüísticos asociados al género no son generales ni sistemáticos. Sin embargo, cuando estos y otros autores se enfren- tan al comportamiento del género en el caso de los sustantivos con referencia personal se ven obligados a integrar el "sexo" en la categoría del género, eso sí, diferenciando entre "sexo biológico" y "sexo semántico"; y aunque afirman que no existe una correspondencia unívoca entre género y desinencia, no obstante, admiten una "orientación general femenina de $-a$ " (Roca, 2005, p. 33); o que "la asociación género-sexo está avalada por un uso dominante, tanto en la amplitud del léxico que es válido, como en la de la comunidad que lo mantiene vigente" (J. A. Martínez, 1978, p. 187). En definitiva, aceptan la vinculación de género gramatical y "sexo", pero la expulsan de la lengua y se la atribuyen al uso:

Son los Usos, y solo los Usos, los hábitos heredados, los intereses y opinión social de una comunidad, los que determinan la asociación de unas formas con unas determinadas sustancias. En suma: la relación "forma-sustancia" -lo mismo que la de "significantesignificado"- es en principio arbitraria: su asociación o motivación", lo mismo que su "desmotivación" o disociación, es cosa que depende de los Usos de la comunidad hablante (J. A. Martínez, 1978, p. 187).

La necesidad de justificar el comportamiento genérico del masculino ha llevado no solo a negarle cualquier contenido de "sexo", sino incluso a rechazar su propia existencia o a confundirlo con un pretendido "género neutro". Así, se mantiene que formalmente sólo existe el femenino: "la marca única [F] definirá el femenino, mientras que los masculinos no llevarán marca, y por tanto formalmente no tendrán género" (Roca, 2005, p. 43). Nuevamente se confunde el género con su expresión morfemática. Por otra parte, la "marca", concepto funcional, que hace referencia a la definición de los elementos lingüísticos en el sistema de oposiciones que constituye la lengua, no puede confundirse con su manifestación formal, como tampoco se puede extraer de ella ningún tipo de contenido sustancial, como más adelante veremos.

En este mismo orden de cosas, los quinientos lingüistas que apoyaron con su manifiesto (http://manifiestolinguistica.weebly.com/, 2012) el artículo de la Real Academia Española firmado por Ignacio Bosque "Sexismo lingüístico y visibilidad de la mujer" (El País, 4 marzo 2012) sostienen la inexistencia del masculino:

... el uso "englobador" (sic) de la expresión "los españoles" no es sexista, pues para que lo fuera "esta [los españoles] debe ser una forma masculina" $y$, según su criterio, eso no está nada claro, puesto que "se podría concluir con idéntica base científica -pro- 
bablemente mayor- que el español carece de género masculino, que la forma que la tradición ha clasificado como masculina en realidad es la ausencia de género y que el único género gramatical que se codifica en español como tal es el femenino".

La razón que esgrimen es la siguiente:

Si la forma cientifico fuera masculina, debería excluir a los miembros de género femenino. Sin embargo, esto no es así. Podemos decir sin contradicción que "El primer científico en identificar la radiactividad fue una científica, Marie Sklodowska", lo cual sería sorprendente si la forma en -o fuera masculina porque el conjunto considerado debería entonces excluir a las mujeres científicas ${ }^{1}$

Se diría que las posibilidades son o bien excluir el contenido lingüístico de "sexo" de la categoría del género, salvando así la posibilidad del masculino de incluir una referencia genérica, o bien, aceptando el contenido lingüístico de "sexo", negar su carácter de auténtico genérico ${ }^{2}$. Efectivamente, esto último es lo que ocurre en muchas de las críticas feministas del lenguaje sexista:

Uno de los fenómenos más graves de discriminación lingüística radica en un aspecto gramatical que articula tanto el castellano como otras muchas lenguas y que consiste en el uso del género masculino como neutro, es decir, utilizándolo como si abarcara masculino y femenino. Esta regla, [...] como el resto de las reglas gramaticales que se han dictado, no es de orden natural, eterno e inmutable, sino un claro reflejo de la visión androcéntrica del mundo y de la lengua (E. Lledó Cunill, 1992, p. 28).

En la misma línea, Bengoechea (2000, p. 36) afirma que el género masculino no abarca al femenino, sino que lo suplanta y "puede causar en las mujeres la negación de sí mismas, un proceso de alienación, de pérdida de identidad (2000, p. 38). Las mujeres se van acostumbrando a renunciar a su identidad sociolingüística y la ambigüedad en la expresión se traduce en el sentimiento de ocupar un lugar marginal en el idioma y en la sociedad. La conclusión: el masculino genérico es el "ladrillo simbólico del patriarcado" (Alario, Bengoechea, Lledó y Vargas, 1995), transposición a las estructuras lingüísticas de la dominación masculina, una herramienta discursiva para excluir simbólicamente a la mujer.

Sin embargo, partiendo de que el género es una categoría mixta o plurifuncional, la dificultad lógica que se plantea en el caso de los sustantivos con referencia personal se resuelve considerando: a) en pri- mer lugar, que la oposición +animado / -animado es operativa para el funcionamiento del género (Arias Barredo, 1995); b) en segundo lugar, admitiendo el doble funcionamiento del masculino en dos planos: uno particular o específico y otro general o inespecífico (Arias Barredo, 1995); y c) en tercer lugar, apelando a los conceptos de marca y neutralización (Márquez Guerrero, 2013).

\subsection{Marca, neutralización y distribución defectiva}

Efectivamente, estos conceptos son esenciales para interpretar el doble funcionamiento del género masculino y la potencial ambigüedad que se deriva de ello. Como es sabido, toda la Fonología praguense se organiza sobre el concepto de sistema, que, frente al inventario, es el conjunto de interrelaciones que definen negativamente, por oposición, a los fonemas. Lo importante no son los elementos aislados, sino el conjunto de oposiciones fonológicas (Trubetzkoy, 1973, p. 60). Por tanto, cada elemento se define por su valor, de forma negativa, relativa. Al tratar de los diferentes tipos de oposiciones distintivas, Trubetzkoy define las oposiciones privativas como "aquellas en las que uno de los miembros se caracteriza por la presencia de una marca y el otro por la ausencia de esa misma marca" (1973, p. 66). "Enfrentados dos fonemas se considerará que uno está marcado respecto del otro si posee algo más que no posee su opuesto, de manera que el fonema marcado es más complejo en su realización y, por ello mismo, menos frecuente en su manifestación sintagmática" (Martínez Celdrán, 1989, p. 44).

La marca \pm define a los dos fonemas que intervienen en una oposición privativa, de ahí que estar marcado negativamente no pueda asimilarse a no tener marca, y a partir de ahí llegar a la afirmación de que tal elemento no existe, como parece deducirse de las palabras de Roca (2005, p. 43): "la marca única [F] definirá el femenino, mientras que los masculinos no llevarán marca, y por tanto formalmente no tendrán género". Dado el enfoque binarista que impera desde R. Jakobson, la marca hace referencia a aquel rasgo distintivo que señala la diferencia entre dos elementos que se oponen; por tanto, la marca negativa define el valor de un elemento tanto como la positiva; no se puede identificar con ausencia de marca, lo cual equivaldría a afirmar que no hay oposición privativa, como tampoco es equiparable a "redundancia" [0], que "consiste en la previsibilidad de una unidad en un contexto determinado" (Martínez Celdrán, 1989, p. 37). Por tanto, los sustantivos masculinos sí tienen formalmente género, el cual se manifiesta siempre en 
la concordancia, $y$, a veces morfemáticamente (morfos $-o,-e, \varnothing)$; en todos los casos, están marcados negativamente con respecto al otro miembro de la oposición, el femenino. Hay, por tanto, dos géneros en español, y no solo femenino, como podría deducirse del planteamiento inicial de Roca, y como afirman los numerosos lingüistas que firman el manifiesto de apoyo a I. Bosque. De hecho, en algún momento, Roca llega a plantearse la existencia de un género unario en español, pero se da cuenta de que por "ciertos hechos semánticos" puede ser contraproducente su defensa (2005, p. 43). Esta interpretación de un género unario en español -tesis que le permitiría afirmar que las formas masculinas no transmiten contenido alguno de "sexo", de ahí que puedan tener un uso genérico- no le permitiría explicar, sin embargo, desde una perspectiva interna a la lengua, los casos en los que, en un plano específico, los sustantivos animados masculinos implican el rasgo 'macho', como en el ejemplo "Ha venido el hijo de María", donde todos los hablantes interpretan que ese hijo es varón, y no por inferencias pragmáticas:

Si no utiliza hija, se inferirá que el referente pretendido no es hembra, $y$, por consiguiente, que es macho, por exclusión biológica, y de ahí la interpretación común (aunque, como estamos viendo, no necesaria) de hijo como macho en estas circunstancias (Roca, 2006, p. 416. Cursiva mía).

Significa 'macho' no por "exclusión biológica” (Roca, 2006, p. 416), algo completamente ajeno al sistema lingüístico, sino por el propio valor de miembro no marcado que el masculino adopta en la oposición de género cuando se da un contexto específico, de pertinencia: no - $a$ : [-'fem', -Hembra]. Al tratarse de una oposición privativa, la negación de un rasgo supone la afirmación de su contrario.

Desde un punto de vista teórico, el determinar cuál de los dos miembros es el marcado y cuál el no marcado tiene que ver con la existencia de neutralización de la oposición y con la frecuencia relativa de aparición de cada miembro. Como es sabido, las oposiciones no tienen la misma fuerza o persistencia en todos los contextos. En determinadas situaciones se suspenden, la marca distintiva deja de ser pertinente y el hablante atiende solo a los rasgos comunes a los miembros de la oposición. En estos contextos, el miembro no marcado (el menos complejo, el más sencillo en su realización, y también el más frecuente, extenso e inclusivo) ocupa todo el espacio funcional. En efecto, en nuestra lengua el masculino es el término no marcado, pues en determinados contextos no especí- ficos en los que la marca distintiva (los rasgos [ $\mathbf{}^{\prime} \mathrm{fem}$ ', \pm 'hembra']) deja de ser relevante tiene la capacidad de hacer una referencia global: "Los alumnos entregarán sus trabajos antes de junio". Por ser el término no marcado, el masculino es el género "por defecto", el que utilizamos en los casos de nominalización de infinitivos verbales, de otras partes de la oración, de oraciones completas o de compuestos de verbo + sustantivo plural. Por la misma razón, es el masculino el género utilizado en la concordancia con sustantivos de diferente género (El niño y su amiga vinieron juntos"), o con pronombres indefinidos ("Nadie está contento con la situación del país").

El hecho de decidir, desde una perspectiva teórica, qué género es el término no marcado tiene que ver, por tanto, con el fenómeno de la neutralización y con la mayor frecuencia de uso. Otra cuestión es por qué el masculino es el término con una frecuencia mayor de uso o el miembro no marcado, qué razones lingüísticas internas (de orientación semántica, por ejemplo, Marcial Morera, 2011) o externas (sociales, culturales, etc.) pueden estar en la base. Así, el que el masculino sea el término no marcado, el que pueda ocupar todo el espacio funcional de la categoría, ha sido interpretado por la corriente de investigación feminista del lenguaje como reflejo en las estructuras lingüísticas de las estructuras sociales, esto es, de la dominación masculina. Esta no deja de ser una hipótesis científicamente indemostrable, aunque es muy probable que la motivación última de la posibilidad de utilizar el masculino con referencia global tenga una raíz en las condiciones históricas, esté basado en la presencia mayoritaria de los varones en todas las esferas de la vida pública y la correspondiente ausencia femenina; no olvidemos que el término no marcado es el de uso más frecuente.

Por otra parte, la marca no puede interpretarse como exclusivamente determinada por el sistema y, por tanto, inmutable. Conviene recordar que en un plano diacrónico se han documentado casos de inversiones en la marcación (Alfonso Vega, 2005). También en un plano teórico, hemos asistido al cambio en nuestra percepción acerca de cuál sea el elemento marcado y el no marcado en una oposición binaria. Así, durante muchos años se consideró que en la oposición $\mathrm{p} / \mathrm{b}$ la marca distintiva era la sonoridad: $\mathrm{p}$ / b: [-sonoro / + sonoro]. Hoy día gracias a los avances tecnológicos, sabemos que no es la sonoridad, sino la tensión el rasgo que permite diferenciar a ese par correlativo (Martínez Celdrán, 1989). El fonema /p/ ha pasado de ser término no marcado por la sonoridad a ser considerado como término marcado de la opo- 
sición de tensión. Por supuesto, se puede argumentar que los sonidos o el léxico de una lengua son más permeables a las influencias extralingüísticas que las categorías gramaticales, mucho más resistentes, lo cual no quiere decir que no se den: baste como ejemplo la desaparición del género neutro latino.

En cualquier caso, estas cuestiones que tratan sobre la motivación semántica última que puede haber en la base de la organización lingüística no pasan de ser hipótesis indemostrables. El hecho del funcionamiento por oposiciones binarias es una característica propia del sistema de la lengua ${ }^{3}$; otra cosa es cuál de los elementos es el marcado y cuál el no marcado. Según los estudios de lingüística cognitiva, "la idea fundamental es que el miembro positivo especifica la relación o dirección normalmente asumida" (Varo Varo, 2004, pp. 24-25; Vigara Tauste, 2009 habla de priming cronológico; cursiva mía; término "positivo" equivale a funcionalmente "no marcado"). En la determinación del miembro no marcado pueden intervenir factores sociales, pues la lengua es un producto social e histórico, pero, desde luego, ese hecho no tiene nada que ver con una decisión voluntaria y razonada por parte de los hablantes ni de los estudiosos de la lengua, como parecen sugerir las palabras de Roca:

"La elección de F por "femenino", como rasgo de género, en lugar de $\mathrm{M}$, por "masculino", con los valores opuestos, es por supuesto arbitraria, aunque no irracional" (Roca, 2005, p. 36).

No compartimos tampoco otras opiniones que suponen una aplicación "peculiar" del concepto de "marca", como la de P. Violi (1991, p. 66):

En el caso del género, el rasgo semántico que funciona como elemento de base es naturalmente el masculino. Así Langendoen (1969) utiliza /+Masculino/ para marcar las entradas masculinas en el léxico, y /-Masculino/ para las femeninas. De la misma forma McCawley (1968)... define las formas /+macho/ /-macho/ como parte de la información semántica referente al género como rol activo en la selección. Otros lingüistas, como Postal (1966) o Chafe (1970) incluyen solamente el rasgo masculino en la información semántica del léxico.

De ahí que concluya con que "En cada caso el femenino siempre coincide con la ausencia de rasgo masculino" (Violi, 1991, p. 66)

En nuestra opinión, en estas interpretaciones se está proyectando la lógica de los procesos sociales al plano de lo lingüístico. La confusión en el plantea- miento del tema aumenta por la utilización, desde ámbitos ajenos a la lingüística, de los tecnicismos propios de nuestra ciencia de forma figurada $y$, por tanto, sin la precisión que la terminología científica exige. Así, como si de una mala traducción se tratara, de género marcado lingüísticamente, el femenino se convierte en género derivado y subalterno:

Un dato común a todos los idiomas de género que se conocen, es la ABSORCIÓN de lo femenino por parte de lo masculino; el término genérico no marcado, $y$ por lo tanto, la BASE, siempre es lo masculino y lo femenino se coloca como TÉRMINO DERIVADO de éste a través de determinadas transformaciones morfológicas (Violi, 1991, p. 68).

Solo partimos del uso para la identificación del masculino como término no marcado. No podemos establecer con certeza las bases culturales, antropológicas, que motivaron la organización de la categoría que permite a los sustantivos masculinos, igual que al genérico hombre, tener la posibilidad de una doble representación: de la especie y del género. Lo cierto es que como el valor genérico -de genus-solo puede determinarse contextualmente (por el cotexto y por el contexto, los conocimientos comunes compartidos), van a ser muy frecuentes los casos de ambigüedad, como ya hemos mencionado, y como la misma RAE en su Nueva Gramática de la Lengua Española (NGLE) reconoce.

Tampoco compartimos otras visiones heterodoxas del concepto de marca como la de Morera (2011), quien parte del carácter no marcado del masculino, $y$, por tanto, de su capacidad de hacer una referencia global, para considerarlo como el género "principal", "esencial" o básico presentando al femenino como una suerte de género secundario o derivado. En nuestra opinión, no se deberían extraer conclusiones sobre el valor semántico del género a partir de lo que es un comportamiento funcional. Morera trata de hallar el valor invariante del género en español; en su opinión, el significado del género gramatical no tiene que ver con el sexo, una interpretación "reduccionista" producto de la confusión de la lengua con la realidad. Situándose, según él, de forma explícita en el plano de la lengua, no del hablar, y partiendo de Hjelmslev (1976, pp. 149-160) para quien el masculino significa 'concentración de la sustancia' y el femenino 'expansión de la sustancia', Morera afirma que

... lo que parece implicar constante e invariablemente el género gramatical es una diferencia de orientación de la sustancia que se encuentra en la base de los signos que determina, que presentan 
siempre significación categorial sustantiva... De un lado, la forma $-o$, tradicionalmente denominada masculina, se caracteriza por orientar la sustancia hacia dentro, hacia ella misma, presentándola como lo que es en sí misma y por sí misma, sin consideraciones relacionales o ampliación de ningún tipo. Digamos que implica una 'orientación centrípeta de la sustancia' que encierra o concentra la sustancia en sí misma, como instancia semántica primaria. [...] Frente a esto, el femenino añade siempre matices muy marcados a la sustancia de base (2011, pp. 33-34).

Morera utiliza criterios puramente sustanciales; queriendo alejarse de la confusión de la lengua con la realidad (género y sexo), ha venido a confundir las categorías lingüísticas con categorías conceptuales o lógicas ("esencia" o "accidente") no definidas previamente ni contrastadas con la realidad.

La distinción de dos posiciones funcionales (pertinencia / neutralización) o dos planos semánticos (-específico / + específico) nos permite mantener el contenido específico de "sexo" para el masculino, y al mismo tiempo la posibilidad de que en una situación inespecífica pueda ocupar todo el espacio funcional de la categoría. Idéntico valor genérico puede adoptar el femenino, como ocurre en persona, víctima, criatura o jirafa. "Lo que es claro es que cualquiera de los dos géneros, en español, puede funcionar a nivel del hiperónimo semántico" (Arias Barredo, 1995, p. 48). Incluso, en algún caso, como modisto / modista, es cuestionable que sea el masculino el término no marcado de la oposición, pues funciona como el excluyente, mientras que modista es el más abarcador. Recordemos que el elemento no marcado aparece con una frecuencia aproximadamente doble de la que aparece el término marcado (Echaide, 1969, pp. 122-123). No se puede hacer una extrapolación desde un valor funcional a una afirmación acerca de la identidad sustancial. Sería algo así como definir al fonema /b/con los rasgos propios del archifonema labial /B/; o como oponer el masculino genérico al femenino específico, es confundir los planos. En el plano específico, también el masculino orienta o proyecta la sustancia 'ser humano' hacia fuera presentándola como una extensión o precisión de ella: [-hembra] $\rightarrow=$ 'macho'; el masculino específico también es una derivación o proyección de la significación invariante de base.

Marca y neutralización son dos conceptos operativos en el funcionamiento de nuestro sistema lingüístico. ¿Por qué entonces numerosas filólogas, críticas del sexismo lingüístico, insisten en las consecuencias discriminadoras que tal uso comporta? Lejos de ser una moda o manifestación "políticamente correcta", la ambigüedad del masculino es un hecho constatado históricamente; de ahí la necesidad de precisión a través de diferentes recursos (especificación, desdoblamiento, barras, etc.) para identificar con claridad la referencia. Las críticas se centran en la utilización abusiva del masculino genérico cuando se utiliza en contextos aparentemente universales siendo que en realidad se hace referencia solo a varones. En estos casos, no podemos hablar de neutralización, pues nos hallaríamos en un contexto de pertinencia; para ser precisos tendríamos que hablar de distribución defectiva. Para que hablemos de neutralización, en un determinado contexto ha de ser posible la ocurrencia de ambos elementos: uno, otro o cualquiera de ellos.

\section{EL USO ABUSIVO DEL MASCULINO GENÉRICO}

Cuando, tras la Revolución Francesa, la Asamblea Nacional aprobó la Declaración de los derechos del hombre y del ciudadano, ni el sustantivo hombre ni el masculino singular ciudadano tenían auténtico valor genérico pese al carácter aparentemente universal del enunciado, pues su referencia era exclusivamente a "varones"; no hace falta recordar que las mujeres entonces no teníamos siquiera derecho al voto. El sexismo ideológico, que olvida a las mujeres y "naturaliza" su ausencia, permitió la no especificación -ahí está el sexismo social y también el discursivo-, que dejó una huella en la lengua en la identificación de los valores genérico y específico del masculino; de ese modo, se llegó a equiparar la noción de persona con las de 'varón' y 'hombre'. Lo criticable es, pues, ese olvido histórico de la especificación, que ideológicamente supone naturalizar la ausencia de la mitad de la especie, y que explica que actualmente las mujeres no se sientan incluidas en esas expresiones. Al incorporarse la mujer a la esfera pública se hace evidente esa asociación del género 'masculino' en su uso "genérico" con el contenido 'varón'. En el discurso, esa asociación es muy evidente en el llamado "salto semántico":

Los ingleses prefieren el té al café. También prefieren las mujeres rubias a las morenas (García Meseguer, 1997). ${ }^{4}$

Por supuesto, es un fenómeno que se produce en el uso determinado por factores sociales y que da origen a un problema de ambigüedad en la identificación referencial. Si atendemos a la eficacia comunicativa, y no buscamos causas -ni, por supuesto, culpables-, lo que es criticable es la imprecisión que puede dar lugar a equívocos. Como señala García Meseguer (1997), si el masculino tiene la posibilidad de funcionar en de- 
terminados contextos como genérico, en los casos en que no lo hace es necesario desambiguar el valor referencial de ese signo marcando que en esta situación está haciendo referencia 'solo a varones'. No hacerlo implica violar la Máxima de Cantidad de P. Grice (1975): "Que su contribución contenga tanta información como la requerida (por las miras coyunturales del intercambio). Que su contribución no contenga más información de la requerida" (cursivas mías). La violación de esta regla pone en marcha un proceso de inferencia del que se extrae una información implícita, a saber: se identifica a la especie humana con el conjunto de los varones y, como consecuencia, se da como algo natural la ausencia de mujeres. De ahí que no resulte nada extraña la impresión de exclusión o invisibilización de aquellas, que no es una cuestión de especial "sensibilidad", sino la interpretación que se infiere del uso de ciertas estrategias comunicativas. Para que se pueda hablar de "neutralización", el rasgo distintivo que constituye la marca ha de ser irrelevante en ese determinado contexto; es decir, en el caso del género, los rasgos [+Fem / -Fem] y ['+Hembra' / '-Hembra'] no han de ser pertinentes desde el punto de vista informativo. Dicho de otro modo, cuando se afirma que el masculino sirve tanto para especificar al 'sexo varón' cuanto para indicar la 'irrelevancia de la información sobre el sexo del referente' se da por sentado que, en el contexto cognitivo y pragmático, existe la posibilidad de que ambas referencias, a varones y a mujeres, a los dos o a cualquiera de ellos, sean posibles. Si no se da esta condición, no podemos hablar de neutralización, sino de distribución defectiva y el masculino no funciona como un auténtico genérico. Por tanto, no son pragmáticamente adecuadas expresiones como la Declaración de los Derechos Universales del Hombre y del Ciudadano, pues el sujeto referencial real es todos los hombres sin excepción, pero en ningún caso se contemplaba la presencia de las mujeres, quienes, por el momento, estaban excluidas de la vida política y de la representación pública. En un contexto tal no puede hablarse de "irrelevancia de la información acerca de la identidad sexual", ni, por tanto, de neutralización de la marca: se trata de un masculino falsamente genérico.

Definimos el discurso sexista como "... el conjunto de rasgos y usos lingüísticos discriminatorios derivados de la situación y la acción social" (Vigara Tauste, 2009 , p. 32). Engloba tanto "las palabras o expresiones fijadas en el vocabulario de la lengua que reflejan ideas sexistas (sexismo léxico)" como las "proposiciones explícitas o implícitas enunciadas en el discurso portadoras de contenido semántico discriminatorio por razón de sexo (sexismo pragmático)" (Díaz Rojo, 2000, p. 45). El discurso es sexista cuando no hace una referencia adecuada a las personas y las discrimina por razón de su sexo en las siguientes circunstancias:

- Cuando en un determinado contexto el rasgo 'sexo', que es relevante, no se refleja formalmente: los Derechos del hombre y del ciudadano.

- Cuando se utiliza la variación en las marcas formales del género para hacer referencia al "sexo" cuando este no es relevante desde el punto de vista informativo, o cuando ya está identificado con precisión a través de otros elementos del contexto: "Nieves Martín y Adolfo Muñoz, traductora y traductor, respectivamente, al castellano de los libros de Harry Potter,...". Una vez que la referencia está claramente identificada, la concordancia ha de realizarse en masculino de acuerdo con las reglas de nuestra lengua. "Nieves y Adolfo, traductores...", si no queremos caer en ultrasexismo (Calero Vaquera, Lliteras Poncel y Sastre Ruano, 2003).

El uso de los falsos genéricos, condicionado por el contexto (histórico y cultural) y sancionado ideológicamente, consiguió identificar lo particular varonil con lo universal humano, convirtiendo al varón en paradigma, centro y medida de todas las cosas. La ambigüedad no está provocada por la vinculación de género y sexo, como señalaba García Meseguer (1991), según el cual la interpretación depende de si los hablantes tienen o no una conexión automática entre género y sexo, hecho que obviamente es evidente en la inmensa mayoría de los sustantivos con referencia personal en un plano específico.

En nuestra opinión, el conflicto, que sí existe, se produce por la confusión de los planos específico / inespecífico confirmada por diferentes estudios (Perissinotto, 1983; McConnell-Ginet, 1988/1992; Nissen, 1991; Demonte, 1991; Fernández Lagunilla, 1991, entre otros). La interpretación general del masculino como específico en enunciados potencialmente universales pone seriamente en duda el concepto de genérico. Por esta ambigüedad, el masculino genérico se revela como insuficiente e impreciso, ya que no solo no designa con transparencia la realidad, sino que incluso nos impide percibir o imaginar cambios en situaciones, aunque se estén produciendo de hecho (Mañeru, 1991, p. 311).

M. Rodríguez Fernández (2009) analiza la evolución en la forma de realizar referencias genéricas en un periodo de tiempo de 30 años, desde 1976 a 2006, 
utilizando textos escritos extraídos de diarios y revistas de ámbito nacional, según las variables sociales de "sexo", "ideología" y "nivel socio-económico" del receptor. En términos generales, la autora constata "el mantenimiento de los sustantivos masculinos plurales como la variable lingüística de mayor rendimiento para la actualización de referencias genéricas" (2009, p. 196), al mismo tiempo que se acusa un descenso considerable en la frecuencia de uso del masculino genérico singular y un aumento correlativo de los sustantivos de género fijo con referentes humanos (especialmente gente y persona). Se observa, dice la autora, "la puesta en marcha de un progresivo fenómeno de sustitución de los masculinos genéricos por parte de los sustantivos de género fijo con referente humano, cuya máxima representación viene de la mano del sustantivo persona" (pp. 200-201). La tendencia es más evidente en las mujeres, y entre estas, en las de clase social media-alta, con un nivel cultural alto y una ideología progresista; por lo que podemos decir que, además de la variable oral / escrito, es fundamental contar con las variables de sexo, clase social - nivel académico e ideología.

La ambigüedad semántica del término hombre es evidente, de ahí la tendencia a sustituirlo por otros términos como persona, aunque también nos parece una medida correcta utilizar varón en lugar de hombre en contextos específicos. Como señala García Meseguer (1991), la utilización del específico varón desterraría la conexión entre el genérico "hombre" y el colectivo "ser humano", con lo cual ya no resultaría invisibilizada la mujer. Es muy probable que sea así, pero tales cambios exigen periodos de tiempo muy largos; mientras eso ocurre, no vemos ningún problema en buscar alternativas, formas de nombrar en las que las mujeres se encuentren realmente incluidas, pues la necesidad de precisión en la identificación referencial es esencial, igual o más importante que el principio de economía.

La asociación entre el valor genérico, "ser humano", y el específico, "varón" no parece ser casual, reflejo aséptico del funcionamiento del sistema, sino una posibilidad de realización del sistema condicionada histórica, cultural e ideológicamente. El mismo condicionamiento histórico y social que explica que hoy los femeninos específicos se extiendan de forma desigual, con mucha más resistencia en unos casos que en otros, dependiendo de las condiciones de producción del discurso y, en concreto, del campo nocional al que pertenece el sustantivo en cuestión, o, dicho de otro modo, dependiendo de la mayor o menor concentra- ción de poder de los varones en el ámbito profesional en cuestión. Una vez que se ha fijado el uso de esos falsos masculinos genéricos (según García Meseguer 1991, una "rutina cultural"), los enunciados donde aparecen resultan muchas veces ambiguos; en todo caso, la interpretación del valor extensivo va a depender siempre de la situación comunicativa. Calero Vaquera, Lliteras Poncel y Sastre Ruano (2003, pp. 94-95) hablan de un Principio de Accesibilidad Mixta (PAM) que "forma parte de nuestra propia "competencia lingüística" [o "competencia cultural"] para interpretar apropiadamente los referentes personales de estos nombres colectivos mixtos, es decir formados necesariamente por personas de ambos sexos". Aunque el contexto lingüístico favorezca una interpretación genérica, el "dominio cognitivo" será el responsable de que los hablantes interpreten el masculino como específico en función de que la presencia de la mujer en un determinado ámbito esté consolidada (sea cotidiana, habitual) o si, en cambio, su presencia es reciente, extraordinaria u ocasional, en cuyo caso la probabilidad de interpretación genérica disminuirá notablemente.

Se ha señalado que la forma hombre es un falso hiperónimo, un genérico impropio, etc., pues son numerosos los ejemplos que muestran que no se da una relación de auténtica inclusión semejante a la que existe, por ejemplo, entre el hiperónimo árbol y el hipónimo abeto:

1a. *"Los árboles, los abetos y los sauces son plantas de vida muy larga".

1b. "Los hombres, las mujeres y los niños representan diferentes manifestaciones del ser humano".

2a. "El abeto es un árbol de hoja perenne".

2b. * "María es un hombre con un fuerte sentido de la responsabilidad".

3. *"El hombre es un animal que amamanta a sus crías".

La polisemia nos muestra dos significados diferentes que coinciden en un mismo significante en distribución complementaria, es decir, con una aparición sistemática en contextos opuestos: hombre 'ser humano' solo funciona en contextos genéricos, de ahí la impropiedad de su uso cuando el contexto lingüístico es específico, es decir, en situaciones directas (García Meseguer, 1977, pp. 175-176) donde es conocido el sexo de la persona a la que nos estamos refiriendo: María, nombre propio identificador de ser humano hembra, o la oración relativa especificativa "que amamanta a sus crías" impiden una referencia de máxima extensión. 
Se trata de una polisemia originada en "cambios de aplicación" (Ulmann, 1987, p. 180).

Aparte de que pueda o no constituir un caso de sexismo lingüístico, el fenómeno interesa

... en la medida en que puede ser considerado como una anomalía más del intercambio comunicativo, situada casi al mismo nivel que otros infortunios del uso lingüístico, como la impropiedad léxica, la ambigüedad, la redundancia o el anacoluto (Calero Vaquera, Lliteras Poncel y Sastre Ruano, 2003).

Ya Aristóteles, que criticó severamente la polisemia, señalaba que "Las palabras de significado ambiguo son útiles sobre todo para permitir al sofista desorientar a sus oyentes". Desde entonces, los filósofos han competido unos con otros en denunciar la polisemia como un defecto del lenguaje y como un obstáculo capital para la comunicación e incluso para el pensamiento claro" (Ullmann, 1987, p. 189).

Los estudios demuestran que el término hombre tiende a ser interpretado como específico en un $90 \%$ de los casos, de ahí que vaya siendo sustituido por otros como persona, ser humano, individuo, gente, etc. con una mayor capacidad de referencia genérica (Perisinotto, 1983; Rodríguez Fernández, 2009).

El rechazo por parte de algunos lingüistas de la tendencia a la creación de femeninos específicos; a evitar el uso extensivo del masculino genérico en aquellos contextos en que es ambiguo; a la aceptación de neologismos, o al uso de estrategias que identifiquen con precisión y claridad la referencia muestra una discrepancia entre la teoría lingüística y el uso de los hablantes. Hace falta recordar que la lengua no es solo un objeto de estudio, sino un instrumento de comunicación al servicio de la comunidad lingüística. Por tanto, cuando introducimos modificaciones en nuestro discurso no es que nos falte "un conocimiento profundo del acto referencial" (Manifiesto en apoyo a D. Ignacio Bosque, 2012) o que no seamos observadores del sagrado "principio de economía", sino que adoptamos innovaciones útiles, que nos sirven para distinguir algún aspecto o matiz necesario que haga realmente eficaz nuestra comunicación. No hay ninguna razón para temer que la lengua se rompa. Las manifestaciones de rigidez e intolerancia hacia los cambios lingüísticos pueden estar originadas en un deseo de inmovilismo melancólico, o de conservadurismo "presentista", como señalaba Manuel Seco (1981), que recordaba a Nebrija, cuando en 1492 dijo que nuestra lengua estaba ya "tanto en la cumbre que más se puede temer el descendimiento de ella que no la subida"; para entonces todavía no se habían escrito la Celestina o el Quijote. Quizás la solución más sencilla sea la que el propio Seco nos indicó: enseñar "a los alumnos sembrándoles el cerebro con el conocimiento de la verdadera riqueza de la lengua, de sus posibilidades creadoras reales."

\section{NOTAS}

1 En el ejemplo, nos encontramos ante un atributo antepuesto temáticamente. El género no funciona igual en los sustantivos y en los elementos que dependen sintácticamente de él, en los que el género es simple marca de concordancia, pues solo el sustantivo soporta el peso de la identificación referencial. Por otra parte, obsérvese indica que se precisa y aclara "una científica" y no solo el nombre de la investigadora. Un ejemplo similar de

\section{BIBLIOGRAFÍA}

Alario, C., Bengoechea, M., Lledó, E. y Vargas, A. (1995). NOMBRA. La representación del femenino y el masculino y en el lenguaje. Madrid: Instituto de la Mujer. Disponible en http://www.ehu.eus/documents/1734204/1884196/Nombra_ La_representacion_del_femenino_y_ el_masculino_en_el_lenguaje.pdf
Roca, "María Márquez es cirujano", ha sido analizado en nuestro trabajo de 2013.

2. Constituye una falacia argumentativa la reducción de una realidad compleja a dos términos polarizados.

3. Nuestra mente tiende a percibir y categorizar la realidad a través de esquemas binarios: "los diversos valores y actitudes sociales propios de un determinado marco o sistema

Alfonso Vega, M. (2005). Inversión de la marcación. Un cambio sintáctico y semántico en la historia del español. Signos lingüísticos, 1, pp. 92-112. Disponible en http://tesiuami.uam.mx/ revistasuam/signoslinguisticos/include/ getdoc . php id $=5 \&$ article $=5 \&$ mode $=p d f$ cultural configuran una "base experiencial" común que se manifiesta [conceptual y lingüísticamente] en forma de binomios compuestos por dos polos" (Varo Varo, 2004, 11-12).

4. De una frase a otra, la voz ingleses salta semánticamente de colectivo de personas a colectivo de varones, lo cual demuestra que en el primer enunciado el masculino estaba utilizado como específico.

Arias Barredo, A. (1995). De feminismo, machismo y género gramatical. Valladolid: Universidad de Valladolid.

Badia Margarit, A. (1967). Aspectos formales del nombre en español. En: Problemas y principios del estructuralismo lingüístico. Madrid: Consejo Superior de Investigaciones Científicas, pp. 43-71. 
Bengoechea, M. (2000). Historia (española) de las primeras sugerencias para evitar el androcentrismo lingüístico. Revista Iberoamericana de Discurso y Sociedad, 3, 2, pp. 33-58.

Benveniste, E. (1989). Problemas de lingüística general. México: Siglo XXI.

Bosque, I. (2012, 4 marzo). Sexismo lingüístico y visibilidad de la mujer. El País. Disponible en http//cultura.elpais.com/cultura/2012/03/02/actualidad/13300717685_771121.html

Calero Vaquera, M. L., Lliteras Poncel, M. y Sastre Ruano, M. A. (2003). Lengua y discurso sexista (Guía de estilo 1). Valladolid: Junta de Castilla y León.

Demonte, V. (1991). Sobre la expresión lingüística de la diferencia. En: Bernis, $C$., Demonte, V., Garrido, E., Calbet, T. y de la Torre, I. (eds.) VIII Jornadas de Investigación Interdisciplinaria. Los estudios sobre la mujer: de la investigación a la docencia. Madrid: Universidad Autónoma, pp. 287-299.

Díaz Rojo, J. A. (2000). Sexismo lingüístico: enfoque etnolingüístico. Español Actual, 73, pp. 39-56.

Echaide, A. M. (1969). El género del sustantivo en español: evolución y estructura. Ibero-Romania, 1, pp. 89-124.

Fernández Lagunilla, M. (1991). Género y sexo: ¿controversia científica o diálogo de sordos? En: Bernis, C., Demonte, V., Garrido, E., Calbet, T. y de la Torre, I. (eds.) VIII Jornadas de Investigación Interdisciplinaria. Los estudios sobre la mujer: de la investigación a la docencia. Madrid: Universidad Autónoma, pp. 319-327.

García Meseguer, A. (1977). Lenguaje y discriminación sexual. Madrid: Cuadernos para el diálogo.

García Meseguer, A. (1991). Sexo, género y sexismo en español. En: Bernis, C., Demonte, V., Garrido, E., Calbet, T. y de la Torre, I. (eds.) VIII Jornadas de Investigación Interdisciplinaria. Los estudios sobre la mujer: de la investigación a la docencia. Madrid: Universidad Autónoma, pp. 80-90.

García Meseguer, A. (1994). ¿Es sexista la lengua española? Una investigación sobre el género gramatical. Barcelona: Paidós.

García Meseguer, A. (1997). Sexismo lingüístico y ambigüedad semántica. Política Científica, 27, pp. 59-60.
García Meseguer, A. (1999). El español, una lengua no sexista. En Fernández de la Torre Madueño, M. D., Medina Guerra, A. M. y Taillefer de Haya, L. (eds.). El sexismo en el lenguaje. Málaga: CEDMA, pp. 51-76.

García Meseguer, A. (2002). El español, una lengua no sexista. Estudios de Lingüística del Español, 16. Disponible en http:// elies.rediris.es/elies16/Garcia.html

González Calvo, M. (1979). El género, ¿̇una categoría morfológica? Anuario de Estudios Filológicos, 2, pp. 51-73.

Grice, H. P. (1975). Logic and Conversation. En Cole, P. y Morgan, J. L. (eds.) Syntax and Semantics (vol. III: Spech Acts). New York: Academic Press [Trad. esp. en Valdés Villanueva, L. M (ed.) (1991). La búsqueda del significado. Lecturas de filosofía del lenguaje. Madrid: Universidad de Murcia.

Gutiérrez Ordóñez, S. (1981). Lingüística y semántica. Aproximación funcional. Oviedo: Universidad de Oviedo.

Heger, K. (1974). Teoría semántica II. Hacia una semántica moderna. Madrid: Alcalá.

Hjelmslev, L. (1976). Sistema lingüístico y cambio lingüístico. Madrid: Gredos.

Lyons, J. (1968/1980). Semántica. Barcelona: Teide.

Lledó Cunill, E. (1992). El sexismo y el androcentrismo en la lengua: análisis y propuestas de cambio. Barcelona: Universidad Autónoma de Barcelona.

Mañeru, A. (1991). El género ciaccidente gramatical o discriminación no accidental? En Bernis, C., Demonte, V., Garrido, E., Calbet, T. y de la Torre, I. (eds.) VIII Jornadas de Investigación Interdisciplinaria. Los estudios sobre la mujer: de la investigación a la docencia. Madrid: Universidad Autónoma, pp. 309-317.

Márquez Guerrero, M. (2013). Género gramatical y discurso sexista. Madrid: Síntesis.

Martinet, A. (1974). Economía de los cambios lingüísticos. Madrid: Gredos.

Martinet, A. (1978). Elementos de lingüística general. Madrid: Gredos.

Martínez, J. A. (1978). Los elementos de la gramática y el género en castellano. En: Conde, M. V. Estudios ofrecidos a Emilio Alarcos Llorach (con motivo de sus XXV años de docencia en la Universidad de Oviedo). Oviedo: Universidad de Oviedo, pp. 165-192.
Martínez, J. A. (2008). El lenguaje de género y el género lingüístico. Oviedo: Servicio de Publicaciones de la Universidad de Oviedo.

Martínez Celdrán, E. (1989). Fonología general y española. Barcelona: Teide.

McConnell-Ginet, R. (1988/1992). Lenguaje y género. En: Newmeyer, F. J. (comp.). Panorama de la Lingüística moderna de la Universidad de Cambridge (vol. IV. El lenguaje: contexto sociocultural). Madrid: Visor.

Menéndez Pidal, R. (1919). Documentos lingüísticos de España (vol I. Reino de Castilla). Madrid: Junta para la Ampliación de Estudios e Investigaciones Científicas, Centro de Estudios Históricos.

Michael, I. (ed.) (1984). Poema de Mio Çid. Madrid: Castalia.

Morera, M. (2011). El género gramatical en español desde el punto de vista semántico. Frankfurt - Berlin - Bruxelles - New York: Peter Lang.

Nissen, U. K. (1991). Sí, primera ministro. ¿Influye la feminización de los títulos de profesión en la interpretación del masculino en sentido extensivo? En: Bernis, C., Demonte, V., Garrido, E., Calbet, T. y de la Torre, I. (eds.) VIII Jornadas de Investigación Interdisciplinaria. Los estudios sobre la mujer: de la investigación a la docencia. Madrid: Universidad Autónoma, pp. 343-361.

Ono, A. (2007). La notion d'énonciation chez Émile Benveniste. Limoges: Lambert-Lucas.

Pérez García, A. (2007). Sexismo lingüístico: una aproximación a los estudios y métodos. En: Fernández Martínez, P. y Pedrero González, A. La mujer y la sociedad de la información. ¿Existe un lenguaje sexista? Madrid: Fragua, pp. 177-205.

Perissinotto, G. (1983). Spanish 'hombre': Generic or Specific? Hispania, 66, 4, pp. 581-592.

Real Academia Española (1920). Gramática de la Lengua Castellana, Madrid: Perlado, Páez y Cía.

Real Academia Española (1931). Gramática de la Lengua Española. Madrid.

Real Academia Española (1973). Esbozo de una nueva gramática de la lengua española. Madrid: Espasa Calpe.

Real Academia Española (2014). Diccionario de la lengua española. Madrid: Espasa Calpe. Disponible en http://www. rae.es/recursos/diccionarios/drae 
Real Academia Española (2004). Informe de la Real Academia Española sobre la expresión violencia de género. Disponible en http://www.uv.es/ivorra/documentos/Genero.htm

Real Academia Española (2009). Nueva Gramática de la Lengua Española. Madrid: Espasa Calpe.

Reyes, G. (1998). El abecé de la pragmática. Madrid: Arco/Libros.

Roca, I. (2005). La gramática y la biología en el género del español (1a parte). Revista Española de Lingüística, 35, 1, pp. 17-44.

Roca, I. (2006). La gramática y la biología en el género del español (2a parte). Revista Española de Lingüística, 35, 2, pp. 397-432.

Rodríguez Fernández, M. (2009). La evolución del género gramatical masculino como término genérico. Madrid: Fundamentos.
Saussure, F. de (1945/1981). Curso de lingüística general. Buenos Aires: Losada.

Trubetzkoy, N. S. (1973). Principios de fonología. Madrid: Cincel.

Trujillo, R. (1976). Elementos de semántica lingüística. Madrid: Cátedra.

Ullmann, S. (1987). Semántica. Introducción a la ciencia del significado. Madrid: Aguilar.

Varo Varo, C. (2003). La polaridad en el lenguaje. Cádiz: Servicio de Publicaciones de la Universidad de Cádiz.

Vigara Tauste, A. M. (2009). Nombrar en femenino. El caso emblemático de 'jueza'. En: Vigara Tauste, A. M. De igualdad y diferencias: diez estudios de género. Madrid: Huerga y Fierro, pp. 21-76.

Vilarnovo Caamaño, A. (1993). Lógica y lenguaje en Eugenio Coseriu. Madrid: Gredos.
Violi, P. (1991). El infinito singular. Madrid: Cátedra.

Zenenko, G. P. (1983). Acerca de la manifestación del género de los sustantivos y adjetivos como categoría gramatical en las lenguas romances ibéricas. Verba, 10, pp. 231-247.

\section{Recursos web}

Acerca de la discriminación de la mujer y los lingüistas en la sociedad: manifiesto de apoyo a D. Ignacio Bosque. [En línea]. Disponible en http://manifiestolinguistica.weebly.com/

Seco, M. Estabilidad y cambio en la estructura de la lengua. Disponible en http:// www.march.es/conferencias/anteriores/voz.aspx?p1=2301 